\title{
EROSIVE AND ABRASIVE POTENTIALS OF SOFT DRINKS AND AIR POLISHING ON NANO-FILLED COMPOSITE RESIN
}

\author{
Enas T. Enan *
}

\begin{abstract}
Introduction: Erosion is a common condition that is related to consumption of acidic food and drinks such as; carbonated drinks and fruit juices that might cause early deterioration of the dental restorations. Abrasion of dental restorations might result from physical factors such as tooth brushing or polishing.

Objective: This study aimed to assess the combined erosive potential of cola soft drink and orange juice, and the abrasive potential of air-polishing, on the surface of nano-filled composite resin restorations via evaluation of microhardness and surface roughness.

Materials and Methods: A total of 60 specimens were prepared from nano-filled composite resin. Specimens were divided into 3 groups according to the immersion media (water, cola, orange juice), and each was further subdivided into 2 subgroups (unpolished or polished). Surface hardness was measured using a digital micro-hardness tester, and surface roughness was recorded using a profilometer. Data were analyzed by one-way analysis of variance (ANOVA) and Tukey's post hoc test.
\end{abstract}

Results: A significant decrease in surface hardness was observed on immersion of nano-filled composite in either cola or orange juice. Except for the control group, the air-polished specimens had significantly higher surface hardness when compared to the unpolished ones. Cola and orange juice had a significant roughening effect on composite resin surface. Further increase in Ra values was recorded after air-polishing of both groups.

Conclusion: Combining beverages immersion with air-polishing may have a profound effect on the surface deterioration of nano-filled composite resin.

KEYWORDS: Nano-filled composite, soft drinks, surface hardness and roughness.

* Assistant Professor, Dental Biomaterials Department, Faculty of Dentistry, Mansoura University, Mansoura, Egypt. 


\section{INTRODUCTION}

Composite resin restorative materials have been widely used for the direct restorations of both anterior and posterior teeth, due to their superior aesthetics, improved physical properties, better bonding systems, curing refinements, and less environmental concerns over amalgam. ${ }^{1,2}$ Currently, three categories have been proposed for the widely used composite resins: microfilled, microhybrid, and nanocomposite. ${ }^{3}$ Nanofill composite resin is composed of both nanomer and nanocluster. Microhybrid and nanocomposites are widely used on both anterior and posterior teeth as universal resin composites. ${ }^{2,3}$

One of the most important properties that determine the durability of dental materials in the oral cavity is their resistance to dissolution or disintegration which is affected by common consumable foods and drinks (e.g., water, carbonated soft drinks, alcoholic drinks, food derivatives). ${ }^{4}$ Studies have shown that resin-based restorations undergo greater micro-morphological damage following an acid challenge for a prolonged time. ${ }^{5}$

Most people think that the consumption of soft drink and fruit juices is not as harmful as generally believed. However, a number of serious health issues was reported to be associated with regular consumption of soft drinks. The inherent acids and sugars have both acidogenic and cariogenic potential resulting in dental caries and enamel erosion, and might affect dental restorations as well., ${ }^{5,6}$

Under oral conditions, esthetic restorations could be exposed to combined effects of light, moisture, oral habits, such as; tobacco use and certain dietary patterns, such as; caffeine intake, where all might lead to external discoloration. ${ }^{7}$

To maintain excellent esthetic properties, resinbased composite restorations should have good color stability and surface smoothness. The surface texture of dental materials has a major influence on plaque accumulation, which might result in gingival inflammation, increased surface staining, and recurrent caries. ${ }^{8}$ Additionally, surface roughness might directly influence the wear behavior and marginal integrity of posterior tooth-colored restorations. ${ }^{9} 10$ Surface roughening of composite resin restorations caused by wear and chemical degradation might affect the restoration gloss and consequently might increase the extrinsic staining. Water sorption might cause softening of the resin matrix, degradation, reduction of stain resistance, and changes in the resin translucency. ${ }^{11-13}$ Therefore, maintaining a smooth and hard restoration surface is of utmost importance for its long-term success.

A wide variety of polishing systems is available for stain removal from teeth and restorations surfaces. The conventional rubber cup and pumice (RCP) method and the air powder polishing (APP) systems are among the most popular stain-removal methods. Nevertheless; questions have been raised regarding their effects on physical properties, surface morphology and color of restorative materials. ${ }^{14}$ It was suggested that air polishing with glycine is a safe and effective de-plaquing technique on tooth structures, and is currently used in clinical practice. ${ }^{15-17}$ However, an in vitro study by Giacomelli L et al ${ }^{18}$ suggested that air polishing might result in an increased surface roughness of commercial nanohybrid resins used in dental restorations. ${ }^{18}$

Although a limited number of studies have been previously reported, yet the uniqueness of the current study is that it aimed to evaluate the combined effect of soft drinks and air-polishing technique on the surface roughness and hardness of nanofilled composite resin. The null hypothesis tested was that neither air-polishing nor soft drinks would affect the surface of the tested nano-filled composite resin. 


\section{MATERIALS AND METHODS}

The study factors included in the current research were: 1- Immersion solutions in three levels; water (control), cola, and orange juice, 2- Air polishing in two levels; one unpolished and one polished group.

\section{Specimens preparation}

Sixty specimens of nano-filled composite resin Filtek $^{\mathrm{TM}}$ Z350XT Universal Restorative (Filtek Z350, 3M-ESPE, St. Paul, MN, USA) included in this study were divided into 6 groups/subgroups (by combining the levels of factors; solutions and polishing). The quantitative variables of response were surface hardness and surface roughness.

Composite resin was manipulated according to the manufacturer's instructions. A stainless steel mold (5 mm diameter x $2 \mathrm{~mm}$ depth) was used for specimen preparation as the material was inserted into the mold cavity in a single increment and covered with a transparent polyester strip held between two glass slides. The glass slides were held firmly during setting to avoid the presence of air voids and to obtain a smooth surface. Then the resin was light-cured for $20 \mathrm{~s}$ through the glass slide, using a light emitting diode (LED) curing unit (Free Light 2, 3M/ESPE, St Paul, MN, USA) with $1000 \mathrm{~mW} / \mathrm{cm}^{2}$ output intensity and $40 \mathrm{~J}$ total energy. Specimens were finished and polished with Sof-lex discs (3M/ESPE, St. Paul, MN, USA) and light orange aluminum grit $(30-\mu \mathrm{m}$ slurry; $3 \mathrm{M}$ ESPE Dental Products 2385P) while keeping the material surface wet. At the end of these procedures, specimens were washed with distilled water for 30 $\mathrm{s}$, dried with paper towels and immersed in water for $24 \mathrm{~h}$ at $37^{\circ} \mathrm{C}$.

\section{Grouping and immersion}

The 60 specimens of composite resin were divided into three groups (20 specimens each), where specimens of group A (control) were immersed in water during the experiment period, while those of group B and C were immersed in Coca-cola $^{\mathrm{TM}}$ (Coca-cola company, Riyadh, KSA) and orange juice (Caesar ${ }^{\mathrm{TM}}$, Abuljadayel Beverages Inc., Jeddah, KSA), respectively. Each group was then divided into 2 subgroups, where specimens of subgroup 1 were not subjected to air polishing, but those of group 2 were air-polished for 10 seconds before testing. The specimens were kept immersed in artificial saliva at $37 \pm 1^{\circ} \mathrm{C}$ during the intervals between immersion cycles. The drinks were used in the temperature of consumption which is about $\pm 4^{\circ} \mathrm{C}$. The specimens were immersed in their specified solutions for 5 minutes in agitation (CT155, Cientec, Piracicaba, SP, Brazil), 5 times a day, with 2 hours intervals. These procedures were repeated for 30 days. ${ }^{13}$

\section{Air polishing}

Air polishing was performed using a standard air-polishing unit (NSK Prophy-Mate Polishing System, Japan) and polishing powder (KaVo PROPHY pearls ${ }^{\circledR}, \mathrm{KaVo}$ Dental, USA), installed according to the manufacturer's instructions. Working pressure was kept at 1.5 to 2.0 Bar. The instrument nozzle was kept perpendicular to the slide surface. Spraying distance was kept constant by holding the nozzle with a clamp. Spraying time was ensured by an aperture with an electronically controlled opening placed between the tip of the instrument and the slide surface. The air-polishing process was always performed by the same trained operator. The instrument powder chamber was refilled after each air-polishing period to ensure maximum reproducibility of powder emission ${ }^{18}$.

\section{Measurement of surface hardness}

Before conducting the test, surfaces of all specimens were thoroughly inspected by a magnifying lens to exclude specimens with any surface defect or voids that could affect the results. Digital micro-hardness tester (FM-7, Future Tech, Tokyo, Japan) with 50 gm loaded diamond indenter 
of equal diagonals, was used to indent specimens surfaces. Vickers hardness number (VHN) of each indent was automatically calculated by the aid of a built-in microcomputer. Each specimen was subjected to 5 indentations (for 5 seconds each) and the mean VHN of each was calculated. ${ }^{19}$

\section{Measurement of surface roughness}

Base line surface roughness ( $\mathrm{Ra}$ ) values were recorded for all the specimens using a digital profilometer (Mitutoyo Surf Test 202 Analyzer; Mitutoyo Corp, Japan). To measure the roughness profile value, the diamond stylus was moved under a constant load of $3.9 \mathrm{~mm}$ across the specimen surface. The instrument was calibrated using a standard reference specimen and then set to travel at a speed of $0.1 \mathrm{~mm} / \mathrm{s}$ with the range of $600 \mu \mathrm{m}$ during testing. This procedure was repeated 6 times for each specimen and the average value was considered to be the Ra value.

\section{Statistical analysis}

The values of surface roughness and surface hardness were submitted to the KolmogorovSmirnov normality test. Data were then analyzed by one-way analysis of variance (ANOVA) and Tukey's post hoc tests for individual comparisons between groups, at a significance level of $5 \%$.

\section{RESULTS}

\section{Surface hardness}

Means and standard deviations obtained from the surface hardness test are shown in (Table 1) and graphically represented in (Figure 1). The highest VHN mean value (60.3) was recorded for the control group A1 in which the specimens were water- immersed and unpolished while group B1 with specimens -immersed in cola and unpolished, showed the lowest mean (39.8). One-way ANOVA (Table 2) showed a significant difference between the tested groups $(\mathrm{p}=0.0001)$.

As proved by Tukey's test, water-immersed group did not show significant difference in surface hardness between the polished (A1) and unpolished (A2) subgroups $(p=0.31)$. On the other hand, the polished subgroups showed significant differences when compared to the unpolished ones $(\mathrm{p}=0.0001)$, in both group $\mathrm{B}$ (cola-immersed) and $\mathrm{C}$ (juiceimmersed).

Comparing surface hardness values of unpolished subgroups (A1, B1, C1), a significant difference was observed between subgroups $\mathrm{A} 1$ and $\mathrm{B} 1 \mathrm{p}=$ $0.0001)$ and between $\mathrm{A} 1$ and $\mathrm{C} 1(\mathrm{p}=0.0001)$, while the difference between subgroups $\mathrm{B} 1$ and $\mathrm{C} 1$ was not significant $(\mathrm{p}=0.35)$.

TABLE (1) Mean and standard deviation for VHN of the studied groups

\begin{tabular}{clll}
\hline \multicolumn{1}{c}{ Groups } & \multicolumn{1}{c}{ Subgroups } & Mean & SD \\
\hline \multirow{2}{*}{ A.water-immersed } & A1.unpolished & $60.3^{\mathrm{A}}$ & 2.5 \\
& A2.polished & $58.9^{\mathrm{A}}$ & 1.9 \\
\hline \multirow{2}{*}{ B. Cola-immersed } & B1. Unpolished & $39.8^{\mathrm{C}}$ & 1.3 \\
\hline \multirow{2}{*}{ C. Juice-immersed } & B2. polished & $54.6^{\mathrm{B}}$ & 1.9 \\
& C1. Unpolished & $41.0^{\mathrm{C}}$ & 1.9 \\
\hline
\end{tabular}




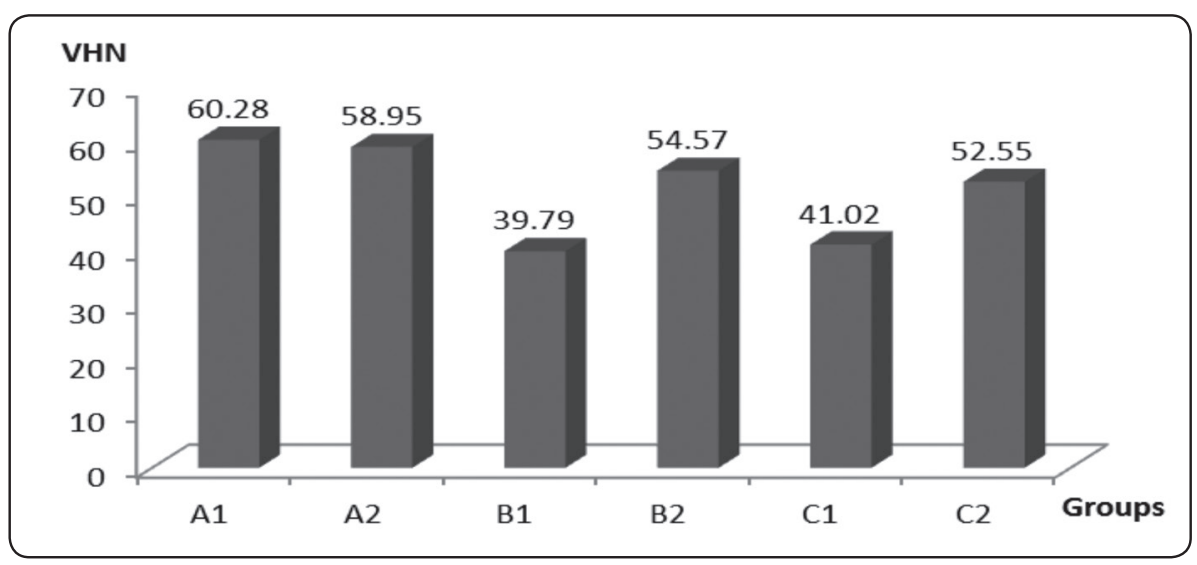

Fig. (1) Mean VHN values of the studied groups

Regarding the surface hardness of air-polished subgroups, significant differences were found between groups A2 and B2 ( $=0.002)$, and between $\mathrm{A} 2$ and $\mathrm{C} 2(\mathrm{p}=0.0001)$. However, the difference between groups $\mathrm{B} 2$ and $\mathrm{C} 2$ was insignificant $(\mathrm{p}=$ 0.13 )

\section{Surface roughness}

Means and standard deviations obtained from the surface roughness test are shown in (Table 3) and represented in (Figure 2). Results of surface roughness (Ra) analyzed by one-way ANOVA test (Table 4) showed a significant difference between the tested groups $(\mathrm{p}=0.0001)$. The highest $\mathrm{Ra}$ mean value $(0.9 \mathrm{~mm})$ was recorded for group B2 in which the specimens were Cola-immersed and airpolished. The lowest Ra mean value $(0.1 \mathrm{~mm})$ was recorded for group A2 specimens that were waterimmersed and air-polished.
Further statistical analysis by Tukey's post hoc test showed nosignificant difference $(\mathrm{p}=0.11)$ between the Ra values of polished and unpolished subgroups (A1, A2) in the water-immersed specimens. On the contrary, the air-polished subgroups showed significant increase in Ra values in both groups B (cola-immersed) and C (juiceimmersed), when compared to the unpolished ones $(\mathrm{p}=0.0001)$.

Comparing the unpolished specimens (subgroups $\mathrm{A} 1, \mathrm{~B} 1, \mathrm{C} 1)$ of the three main groups, revealed significant differences between them $(p=0.0001)$, indicating a significant effect of the immersion solution on the surface roughness. On comparing the polished specimens (subgroups A2, B2, C2), the difference between subgroups $\mathrm{C} 2$ and $\mathrm{B} 2$ $(\mathrm{p}=0.82)$ was not significant, while subgroup A2 was significantly different $(\mathrm{p}=0.0001)$ from both subgroups.

TABLE (2) One-way analysis of variance (ANOVA) for VHN results

\begin{tabular}{lccccc}
\hline \multicolumn{1}{r}{ Source of variation } & SS & df & MS & F & P-value \\
\hline Between Groups & 1948.5 & 5 & 389.7 & 95.5 & .000 \\
Within Groups & 97.9 & 24 & 4.1 & & \\
Total & 2046.4 & 29 & & \\
\hline
\end{tabular}


TABLE (3) Mean and standard deviation for surface roughness Ra (mm) of the studied groups

\begin{tabular}{llll}
\hline \multicolumn{1}{l}{ Groups } & \multicolumn{1}{c}{ subgroups } & Mean & SD \\
\hline \multirow{2}{*}{ A. water-immersed } & A1. unpolished & $0.2^{\mathrm{D}}$ & 0.1 \\
& A2. polished & $0.1^{\mathrm{D}}$ & 0.1 \\
\hline \multirow{2}{*}{ B. Cola-immersed } & B1. Unpolished & $0.6^{\mathrm{B}}$ & 0.1 \\
& B2. polished & $0.9^{\mathrm{A}}$ & 0.2 \\
\hline \multirow{2}{*}{ C. Juice-immersed } & C1. Unpolished & $0.5^{\mathrm{C}}$ & 0.1 \\
& C2. polished & $0.9^{\mathrm{A}}$ & 0.2 \\
\hline
\end{tabular}

Means with the same superscripted letter are not significantly different at $p \leq 0.05$

TABLE (4) One-way analysis of variance (ANOVA) for Ra (surface roughness).

\begin{tabular}{cccccc}
\hline Source of variation & SS & df & MS & F & P-value \\
\hline Between Groups & 2.8 & 5 & 0.6 & 30.2 & 0.0001 \\
Within Groups & 0.4 & 24 & 0.02 & & \\
Total & 3.3 & 29 & & \\
\hline
\end{tabular}

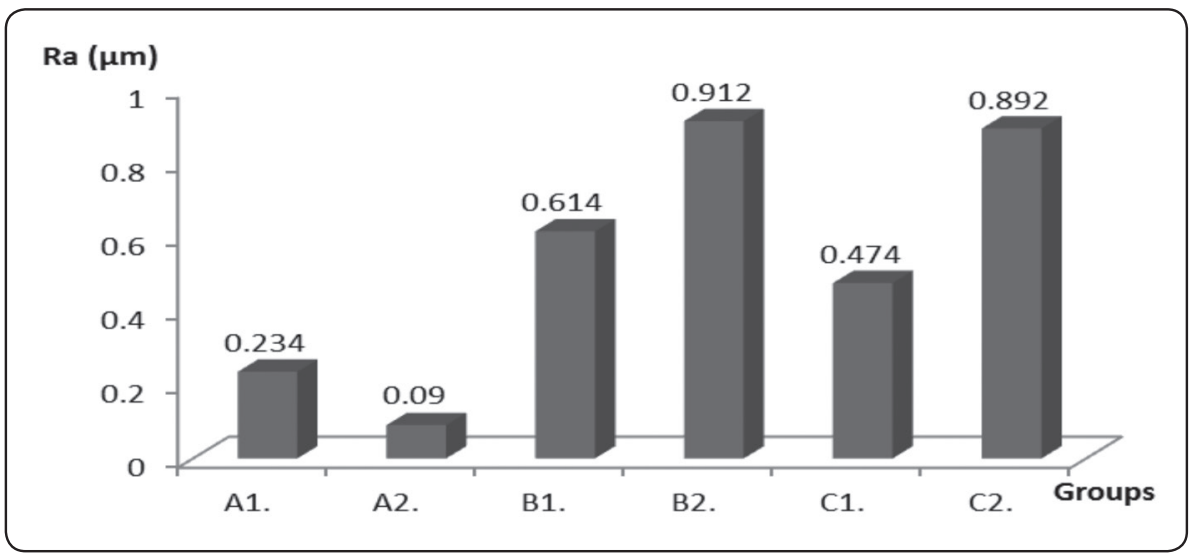

Fig. (2) Mean $\mathrm{Ra}(\mu \mathrm{m})$ values of the studied groups

\section{DISCUSSION}

Degradation in the oral cavity is a complex process that may result from chemical or physical factors. Chemical degradation, or erosion, occurs due to food, drinks or chemicals of varying $\mathrm{pH}$. On the other hand, physical factors, such as tooth brushing or polishing, may lead to abrasion of both teeth and restorations. ${ }^{20}$
Studies have shown that any drink having a $\mathrm{pH}$ of 5.5 or below will wear away the enamel. Normal saliva has a $\mathrm{pH}$ of around 6.8. Whereas pure orange juice has a $\mathrm{pH}$ of 3.5 , and coca cola has a $\mathrm{pH}$ of 2.5. ${ }^{21}$ Excessive tooth contact with acidic drinks for a long periods results in loss of hard tissues, due to the fact that the highly acidic nature leads to change in surface texture. ${ }^{22}$ Like natural tooth, the effect 
of these acidic drinks on the restorative materials might not be undermined.

Physical abrasion has been reported with all polishing methods currently in use to reduce plaque accumulation and staining on different dental structures and biomaterials. ${ }^{23,24}$

Based on the reality that soft drinks are widely consumed by persons of different age groups, and as polishing techniques are becoming more demanded by patients, this study aimed to assess the combined erosive potential of these commonly consumed soft drinks and abrasive potential of air-polishing on the surface of nano-filled composite resin material using the micro-hardness and surface roughness testing.

This study showed that both cola and orange juice caused a significant decrease in surface hardness of nano-filled composite resin specimens when compared to the water-immersed specimens. After immersion in different solutions, the specimens of subgroup 2 from each main group were subjected to air polishing and VHN was measured again. Air polishing significantly improved surface hardness of the cola-immersed and juice immersed specimens, while its effect on the water-immersed ones was insignificant.

On the other hand, analysis of $\mathrm{Ra}$ values revealed a significant roughening effect of both cola and orange juice on the tested specimens. Air-polishing after specimens immersion did not improve surface quality but further aggravation of the surface roughening was noticed in both cola and juice-immersed subgroups. However, airpolishing caused some smoothening effect on the water-immersed specimens, but it was insignificant. These findings were not surprising, since they can be related to the acidic $\mathrm{pH}$ of cola and orange juice, which caused softening and degradation of the organic matrix of composite resin, and penetration of water molecules; leading to sorption and hydrolysis of the material. ${ }^{25}$ The high content of organic matrix in nano-filled composites could be the reason behind higher susceptibility to water absorption and material disintegration. ${ }^{26}$ As airpolishing abrasion tends to remove the softened outer layer of resin matrix, leaving the protruding harder filler particles, a rougher and harder surface was produced. Since the nano-filled composite resin contains greater surface area-to-volume ratio of their filler particle system, this might have caused them to suffer higher surface roughness as compared to other resin based materials. ${ }^{27}$

Maganur et al ${ }^{22}$ reported significant reduction in microhardness of nano-filled composite resin when immersed in different beverages for 24 hours. They concluded that the low $\mathrm{pH}$ drinks have detrimental effects on the longevity of the restorative materials. In another study ${ }^{28}$, researchers have quoted that the type of immersion solutions and the composition of soaked materials are important factors related to dissolution of dental composite resin materials. Other researchers ${ }^{20,29-31}$ have claimed that exposure of composite resin to low-pH liquids can have a deleterious effect on their mechanical properties, and assumed that these shortcomings can be overcome by the introduction of the more promising class of materials lately called nanocomposites.

The abrasive influence of polishing methods was proved by previous researches ${ }^{15,16}$. A study by da Costa et al ${ }^{32}$ evaluated the effect of dentifrices on the gloss and surface roughness of composite resin after tooth brushing. It was concluded that there was a significant reduction in gloss and increase in surface roughness after brushing with all dentifrices. ${ }^{32}$ They added that composite resins containing smaller average fillers showed less reduction in gloss and less increase in surface roughness as compare to resins with larger fillers.

Voltarelli et al 20 examined the effect of chemicals and tooth brushing on surface roughness of composite resins. Their results, which were confirmed by SEM images, demonstrated the 
negative effect of chemical solutions and mechanical abrasion on composite resin surface.

Consequently, the current study at least confirmed the erosive potential of certain weak acids present in different juices and drinks; which are a potentially damaging factor that the public should be aware of. It also proved that combining beverages with air-polishing has a profound effect on the surface deterioration of nano-filled composite. These results were consistent with the other studies done.

\section{CONCLUSION}

Within the limitations of this study, we have shown that weak acids which are present in different soft drinks have a great negative effect on the surface hardness and roughness of nano-filled composite resin material, Air-polishing tends to antagonize the softening effect of soft drinks on nano-filled composite resin surface. Air-polishing might produce smoother surfaces of the waterimmersed nano-filled composite resin, but not with beverages-immersed resin. Combining beverages immersion with air-polishing may have a profound effect on the surface deterioration of nano-filled composite resin.

\section{REFERENCES}

1. Lee I, Chang J, Ferrance J. Slumping resistance and viscoelasticity prior to setting of dental composites. Dent Mat 2008;24:1586-93.

2. Gönülol N, Y1lmaz F. The effects of finishing and polishing techniques on surface roughness and color stability of nanocomposites. J Dent 2012;40:64-70.

3. Senawongse P, Pongprueksa P. Surface roughness of nanofill and nanohybrid resin composites after polishing and brushing. J Esth Rest Dent 2007;19:265-75.

4. Han L, Okamoto A, Fukushima M, Okiji T. Evaluation of flowable resin composite surfaces eroded by acidic and alcoholic drinks. Dent Mater J 2008;27:455-65.

5. Abu-Bakr N, Han L, Okamoto A, Iwaku M. Changes in the mechanical properties and surface texture of compomer immersed in various media. J Prosthet Dent 2000; $84: 444-52$

6. Cheng R, Yang H, Shao MY, Hu T, Zhou XD. Dental erosion and severe tooth decay related to soft drinks: A case report and literature review. J Zhejiang Univ Sci B 2009;10:395-9.

7. Al-Nahedh H,Awliya W. The effectiveness of four methods for stain removal from direct resin-based composite restorative materials. Saudi Dent J 2013;25:61-67.

8. Morgan M. Finishing and polishing of direct posterior resin restorations. Pract Proced Aesthet Dent 2004;16:211-17.

9. Yap AU, Tan S, Teh TY. The effect of polishing systems on microleakage of tooth coloured restoratives: part 1 . Conventional and resin-modified glasseionomer cements. J Oral Rehabil 2000;27:117-23.

10. Ryba TM, Dunn WJ, Murchison DF. Surface roughness of various packable composites. Oper Dent 2002;27:243-7.

11. Shah MB, Ferracane JL, Kruzic JJ. R-curve behavior and toughening mechanisms of resin-based dental composites: effects of hydration and post-cure heat treatment. Dent Mater 2009;25:760-770.

12. Fontes ST, Fernández MR, de Moura CM, Meireles SS. Color stability of a nanofill composite: effect of different immersion media. J Appl Oral Sci 2009;17:388-391.

13. Lepri CP and Palma-Dibb RG. Surface roughness and color change of a composite: Influence of beverages and brushing.. Dent Mat J 2012;31:689-696.

14. Erdemir U, Yildiz E, Eren M, Ozsoy A, Topcu F. Effects of polishing systems on the surface roughness of toothcolored materials. J Dent Sci 2013;8:160-169.

15. Petersilka GJ, Faggion CM Jr, Stratmann U, et al. Effect of glycine powder air-polishing on the gingiva. J Clin Periodontol 2008;35:324-332.

16. Petersilka GJ, Bell M, Häberlein I, Mehl A, Hickel R, Flemmig TF. In vitro evaluation of novel low abrasive air polishing powders. J Clin Periodontol 2003;30:9-13.

17. Petersilka GJ, Steinmann D, Häberlein I, Heinecke A, Flemmig TF. Subgingival plaque removal in buccal and lingual sites using a novel low abrasive air-polishing powder. J Clin Periodontol 2003;30:328-333.

18. Giacomelli L, Salerno M, Derchi G, Genovesi A, Paganin PP, Covani U. Effect of air polishing with glycine and bicarbonate powders on a nanocomposite used in dental 
restorations: an in vitro study. Int J Periodont Resto Dent 2011;31:51-6.

19. Chan KC, Swift EJ. Effects of resin-compatible cavity varnishes on composite resin micro-hardness. J Prosthet Dent 1992;67:791-793.

20. Voltarelli FR, dos Santos-Daroz CB, Alves MC, Cavalcanti AN, Marchi GM. Effect of chemical degradation followed by toothbrushing on the surface roughness of restorative composites. J Appl Oral Sci 2010;18:585-90.

21. Seow WK, Thong KM. Erosive effects of common beverages on extracted premolar teeth. Aust Dent J 2005;50:173-178.

22. Maganur PC, Prabhakar AR, Satish V, Namineni S, Kurthukoki A. Erosive effect of soft drink and fresh fruit juice on restorative materials. World J Dent 2013;4:32-40.

23. Arabaci T, Ciçek Y, Ozgöz M, Canakçi V, Canakçi CF, Eltas A. The comparison of the effects of three types of piezoelectric ultrasonic tips and air polishing system on the filling materials: An in vitro study. Int J Dent Hyg 2007;5:205-210.

24. Petersilka GJ, Tunkel J, Barakos K, Heinecke A, Häberlein I, Flemmig TF. Subgingival plaque removal at interdental sites using a low-abrasive air polishing powder. J Periodontol 2003;74:307-311.

25. Tanthanuch S, Kukiattrakoon B, Siriporananon C, Omprasert N, Mettasitthikorn W, Likhitpreeda S, et al. The effect of different beverages on surface hardness of nanohybrid resin composite and giomer. J Conservat Dent. 2014;17:261-265.

26. Yonikoglu N, Duymus ZY, Yilmaz B. Effects of different solutions on the surface hardness of composite resin materials. Dent Mat J 2009;28:344-351.

27. Khan AA, Siddiqui AZ, Al-Kheraif AA, Zahid AA, Divakar DD. Effect of different $\mathrm{pH}$ solvents on micro-hardness and surface topography of dental nano-composite: An in vitro analysis. Pak J Med Sci 2015;31:854-859.

28. Munchow EA, Ferreira ACA, Machado RMM, Ramos TS, Rodrigues-Junior SA, Zanchi CH. Effect of acidic solutions on the surface degradation of micro-hybrid composite resins. Braz Dent J 2014;25:321-326.

29. Sideridou ID, Karabela MM, Vouvoudi EC. Physical properties of current dental nanohybrid and nanofilled light cured resin composites. Dent Mat 2011;27:598-607.

30. Gharatkar AA, Irani R, Shiraguppi V, Hegde V. Effect of cola, orange juice, and wine on surface microhardness of nano-composites: An in vitro study. J Dent Orofac Res 2014;10:16-20.

31. Cengiz S, Sarac S, Özcan M. Effects of simulated gastric juice on color stability, surface roughness and microhardness of laboratory processed composites. Dent Mater J 2014;33:343-348.

32. Da Costa J, Adams-Belusko A, Riley K, Ferracane JL. The effect of various dentifrices on surface roughness and gloss of resin composite. J Dent 2010;38:123-8. 